\title{
Buen Vivir Andino: Resistência e/ou alternativa ao modelo hegemônico de desenvolvimento
}

KLAus Pereira da SiLVA

Universidade Castelo Branco / Escola Superior de Gestão e TeCnologia, RIo de Janeiro - RJ, Brasil

ANA LUCIA GUEDES

Fundação Getulio Vargas / Diretoria de AnÁlise de Políticas Públicas (DAPP), Rio de Janeiro - RJ, Brasil

\begin{abstract}
Resumo
Este ensaio teórico problematiza a ética do Buen Vivir como forma de resistência e/ou alternativa ao modelo hegemônico de desenvolvimento que tem sido disseminado e implementado por organizações internacionais e corporações. Após a declaração das Nações Unidas sobre os direitos indígenas, em 2007 (MAMANI, 2010), o Buen Vivir alcançou status oficial nas Constituições do Equador e da Bolívia. O Buen Vivir é uma visão de mundo distinta da ordem internacional liberal institucionalizada no pós-II Guerra Mundial; fundamenta-se nas noções de cosmovisão relacional e pluriverso (ESCOBAR, 2011), multiverso (MAMANI, 2010) ou ecosofia andina (ESTERMANN, 2013), enunciados no Sul e subalternizados por mais de cinco séculos de colonialidade. Com base nestas noções, o ensaio enfatiza a importância de repensar, segundo uma abordagem decolonial, o papel desempenhado pelos Estados e organizações governamentais internacionais no que diz respeito ao desenvolvimento local. A análise crítica da literatura sugere a existência de múltiplas visões acerca do desenvolvimento que devem ser debatidas no âmbito de estudos organizacionais.
\end{abstract}

Palavras-chave: Buen Vivir. Desenvolvimento. Globalização. Neoliberalismo. Capitalismo.

\section{Buen Vivir Andino: Resistance and/or alternative to the model of hegemonic development}

\begin{abstract}
This article problematizes the ethics of Buen Vivir as a form of resistance and/or alternative to the model of hegemonic development that has been disseminated and implemented by international organizations and corporations. After the declaration of the United Nations on the rights of indigenous people in 2007 (MAMANI, 2010), the Buen Vivir achieved official status in the Constitutions of Ecuador and Bolivia. Buen Vivir is distinct worldview from the hegemonic liberal international order institutionalized post World War II; it is grounded on the notions of relational cosmovision and pluriverse (ESCOBAR, 2011), multiverse (MAMANI, 2010) or andean ecosophy (ESTERMANN, 2013) which have been enunciated in the South and subalternized by over five centuries of coloniality. Based on these notions, the article emphasizes the importance to rethink, following a decolonial approach, the role played by States and international governmental organizations regarding local development. The critical analysis of the literature suggests the existence of multiple worldviews regarding development that must be debated in the field of organizational studies.
\end{abstract}

Keywords: Buen Vivir. Development. Globalization. Neoliberalism. Capitalism.

\section{Buen Vivir Andino: Resistencia y/o alternativa al modelo hegemonico de desarrollo}

\section{Resumen}

En este ensayo teórico se aborda la ética del Buen Vivir como forma de resistencia y/o alternativa al modelo hegemónico de desarrollo que ha sido difundido e implementado por organizaciones y corporaciones internacionales. Después de la declaración de las Naciones Unidas sobre los derechos indígenas en 2007 (MAMANI, 2010), el Buen Vivir alcanzó estatus oficial en las constituciones de Ecuador y Bolivia. El Buen Vivir es una visión de mundo distinta del orden internacional liberal institucionalizado después de la Segunda Guerra Mundial; se fundamenta en los conceptos de cosmovisión relacional y pluriverso (ESCOBAR 2011), Multiverso (MAMANI, 2010) o ecosofía andina (Estermann de 2013), enunciados en el sur y subalternizados durante más de cinco siglos de colonialidad. Sobre la base de estos conceptos, este ensayo enfatiza la importancia de repensar, de acuerdo con un enfoque decolonial, el papel de los estados y las organizaciones gubernamentales internacionales en materia de desarrollo local. El análisis crítico de la literatura sugiere la existencia de múltiples visiones sobre desarrollo, que deben ser debatidas en el ámbito de los estudios organizacionales.

Palabras clave: Buen Vivir. Desarrollo. Globalización. Neoliberalismo. Capitalismo. 


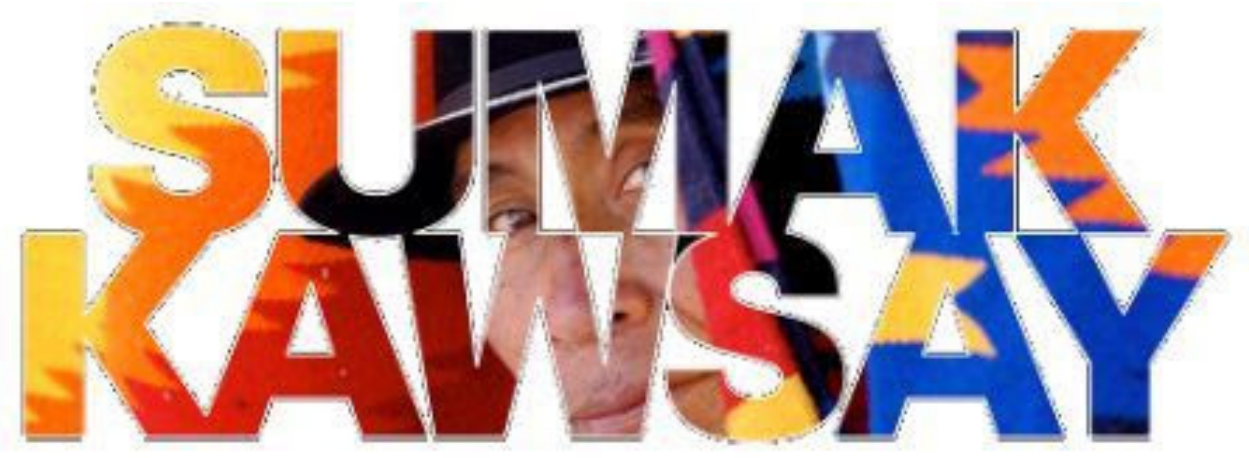

\section{INTRODUÇÃO}

A partir do último quarto do século XX, intensificaram-se as relações transnacionais originadas no sistema de produção, nos fluxos migratórios, financeiros, e de informações, que marcam um fenômeno denominado de "globalização", em que convergem vértices político, econômico, cultural, religioso, social e jurídico para uma realidade complexa (SANTOS, 2006). Tal fenômeno aparenta uma existência universal em um mundo sem fronteiras, mas esconde dicotomias concretas entre esta aparência e as diversidades locais.

Pela amplitude do seu escopo, esse fenômeno, que define alterações na forma como podemos compreender o mundo e vivê-lo, abriga situações problemáticas de ordem econômica, ambiental, política e social, consequentes de um modelo ocidental de progresso, de desenvolvimento, da relação do humano com a natureza, do direito, da cultura, dentre outras questões relevantes para os estudos organizacionais e os estudos internacionais em gestão/administração do desenvolvimento.

Propomos evidenciar neste ensaio teórico alguns problemas consequentes do modelo de desenvolvimento dominante tendo por base Santos (2006), Ibarra-Colado (2006), Santos (2011a; 2011b) e Banerjee (2003; 2011). Consequentemente, o ensaio engaja-se na perspectiva de pluriversalidade para a construção de conhecimentos que devem unir as preocupações de desenvolvimento com as de administração/gestão do desenvolvimento. E, ao fazê-lo, reconhece a existência e dá voz a saberes tradicionais subalternizados/cooptados por um projeto de governança global gestado no Atlântico-Norte, instrumentalizados por agentes supranacionais que, por um olhar mais atento, ilustra os lados mais perversos da modernidade eurocêntrica, como enfatizado por Cooke e Faria (2013).

Mais especificamente, segundo Cooke (2004) esse modelo, que adota uma visão particular da globalização, resulta em uma gestão do Terceiro Mundo (na denominação do autor, termo cunhado no período da Guerra Fria para representar o movimento dos países não alinhados às áreas de influência dos Estados Unidos e da União Soviética) feita por agentes supranacionais com princípios característicos da gestão dos negócios. Como contribuição para este debate, problematizamos a ética do Buen Vivir como uma forma de resistência e/ou alternativa ao modelo hegemônico de desenvolvimento que tem sido disseminado e implementado, principalmente pelo Banco Mundial.

Na literatura, o conceito do Buen Vivir, identificado como um conjunto de ideias ontologicamente distintas das premissas neoliberais, foi estudado por León (2008), Boff (2009), Salgado (2010), Acosta (2010), Gallegos (2010), Mamani (2010), Choquehuanca (2010), Gudynas e Acosta (2011), Gudynas (2011) e Estermann (2013). Estas abordagens críticas pretendem edificar um constructo que represente uma alternativa de desenvolvimento para os povos (ou nações). Para Mignolo (2005), o Buen Vivir pode ser interpretado como manifestação de descolonização epistêmica, ou seja, um pensamento que se desprende e abre possibilidades outrora colonizadas pela racionalidade moderna imperial europeia. No entanto, este ensaio reconhece as controvérsias e debates acerca das "[...] diferentes versões do Buen Vivir praticadas nas regiões Andinas da 
América Latina [...]", que foram "[...] apropriadas pelos mecanismos coloniais de cooptação e de contenção de sub-conhecimentos [...]" para resultar em "[...] uma perspectiva de diversidade universal ao invés de diversidade decolonial" (FARIA, 2015, p. 142) ao longo do tempo.

O Buen Vivir ganhou contornos formais e oficiais por meio da sua adoção pela Constituição da República do Equador e Constituição do Estado Plurinacional da Bolívia, nos anos de 2008 e 2009 respectivamente. Estas reformas constitucionais podem ser compreendidas como marco simbólico e concreto de resistência do Sul (dito não desenvolvido ou em desenvolvimento) ao domínio do Norte (ocidental e desenvolvido). Portanto representam especial relevância contextual em escalas global, regional e local para as organizações públicas e privadas nas dimensões econômica, política e social.

Nesse contexto, Vainer (2006, p. 27) afirma que as disputas políticas e ideológicas estão presentes em diversas escalas e as suas narrativas formulam estratégias, táticas e configuram "arenas e objetos de disputas". Consequentemente, o poder não se concentra em uma ou outra escala, mas na "[...] capacidade de articular escalas, de analisar e intervir de modo transescalar" (VAINER, 2006, p. 28) no âmbito de desenvolvimento local.

O conjunto de ideias que caracteriza o Buen Vivir como uma visão de mundo distinta da ordem hegemônica dominante funda-se na noção de cosmovisão relacional (ESCOBAR, 2011) ou ecosofia (ESTERMANN, 2013). Tais ideias, que serão analisadas neste ensaio, dão conta de resgatar os saberes tradicionais andinos (preexistentes à colonização europeia na América, até então chamada Abya Yala por povos autóctones), e a relação não dual, mas sim de unidade, entre ser humano e natureza. O resgate desta relação que vê o ser humano como parte da natureza implica necessariamente em uma série de alterações de ordem prática nos campos político, econômico e social, além do espiritual, que abriga disputas entre o hegemônico e o tradicional (agora equivalente de alteridade), nem sempre notórias, evidentes, mas com abrangência para além do local de origem (o Sul da América) em um contexto de globalização.

Este ensaio está estruturado em três partes, além desta breve introdução. A primeira apresenta abordagens críticas da globalização evidenciando os problemas de um processo de dominação, sobretudo epistêmica, que dissemina e implementa um modelo de desenvolvimento (com a promessa de progresso) perverso para povos e indivíduos. A segunda descreve o Buen Vivir como um constructo ontologicamente distinto do pensamento ocidental neoliberal capitalista - adotado nas Constituições do Equador e Bolívia. Por fim, reflete sobre um Buen Vivir resistente e translocal, sobretudo por suas raízes tradicionais, anteriores à globalização neoliberal, como contribuição para estudos organizacionais e de gestão/administração do desenvolvimento.

\section{VISÃO CRÍTICA DA GLOBALIZAÇÃO NEOLIBERAL}

A globalização não é um fenômeno natural, homogêneo e harmonioso, mas conscientemente produzido, heterogêneo e conflituoso. Sua relação com os problemas contemporâneos pode ser entendida como resultado da ineficácia dos atores internacionais, dos governos e das organizações locais, supondo que a eficácia permitisse promover as soluções para problemas como a desigualdade e a degradação ambiental.

Segundo Santos, trata-se de um movimento ideológico e político que obscurece a noção de Norte e Sul e produz desigualdades: globalização "[...] é um conjunto de trocas desiguais pelo qual uma determinada condição, entidade ou identidade de um local estende a sua influência para além das suas fronteiras e, ao fazê-lo, desenvolve a capacidade de designar como própria em outro local sua condição, entidade ou identidade" (SANTOS, 2006, p. 395-396). Por isso, uma condição não nasce global, ela é fruto do sucesso de um processo de globalização de um certo localismo, em outras palavras: condições globais com raízes locais.

Santos (2006) aporta a noção de "localismo globalizado" como um processo bem-sucedido de mundialização de um fenômeno local que se materializa no idioma, na música, nos hábitos, na culinária, etc. No entanto, identifica um "globalismo localizado": efeitos locais causados por tal fenômeno que se globalizou e que impactam os modos de vida locais, incluindo-se meios de produção agrícola e a destruição dos recursos naturais em benefício da indústria, como problematizado por Misoczky e Böhm (2013). Cabe desmistificar que o fenômeno, que ocorre em um tempo-espaço determinado, com agentes emissores e receptores, cujas ações produzem efeitos colaterais nos demais, resulta da configuração de poder entre os Estados-Nação dominantes do Norte e os dominados do Sul. 
Consequentemente, caberiam neste ensaio questionamentos a respeito do Sul: (1) se seria capaz de globalizar seus localismos com vistas a um modo de vida alternativo; (2) se teria capacidade de resistir ao globalismo localizado para reduzir os impactos nos modos de vida locais. Respostas negativas a estas questões estão na história das relações econômicas contemporânea: nas tentativas de sobrevivência, desenvolvimento e progresso dos Estados-Nação chamados de subdesenvolvidos ou em desenvolvimento em uma ordem neoliberal hegemônica dominada por uns poucos Estados-Nação, denominados de desenvolvidos.

Em outras palavras, as tentativas de desenvolvimento do Sul resultam equivocadas porque se utilizam de epistemologias do Norte. Nesse processo de reprodução do modelo dominante, o Sul negligencia seu locus de enunciação, os saberes tradicionais e suas epistemologias. É possível reconhecer ainda, de acordo com Mignolo (2005), Escobar (2004, 2005 e 2011), Dussel e Ibarra-Colado (2006) e Quijano (2012), uma negligência do Sul a respeito de suas ontologias tradicionais.

O desenvolvimento e o progresso, na ótica do sistema capitalista global, rumam para um governo mundial sob a égide do fundamentalismo do mercado, em que se subordinam os Estados e as sociedades. A instrumentalidade neoliberal formula uma noção conveniente sobre soberania e liberdade, impõe ao mundo uma universalidade de consciência e conhecimento, cria dogmas que são aprimorados e reproduzidos por organizações internacionais, corporações transnacionais, multinacionais e locais e, por fim, privilegia o capital como única via para a satisfação humana individualmente e em sociedade (DUSSEL e IBARRA-COLADO, 2006). A cultura de consumo de massa em múltiplas escalas normalizada na vida das grandes cidades, e já nas zonas rurais, é um reflexo desse modelo de desenvolvimento, o que Veiga (2010) explica comumente pelo desempenho do Produto Interno Bruto (PIB) per capita.

O processo pelo qual o Sul tenta, em vão, alcançar desenvolvimento e progresso por meio do modelo hegemônico não é natural, mas sim operacionalizado intencionalmente pelo Norte, com a racionalidade que agentes internacionais logram executar. Opera com destaque neste processo o Banco Mundial, por meio de princípios próprios da gestão de negócios, aplicados aos países em desenvolvimento e que resulta em uma gestão do Terceiro Mundo, sob os auspícios do discurso de proteção dos pobres e marginalizados (COOKE, 2004). Os princípios aplicados pelo Banco Mundial para gerir o Terceiro Mundo dificultam a globalização dos localismos do Sul e a possibilidade de redução dos impactos locais da globalização neoliberal e, assim, torna o modelo universal ao subjugar saberes tradicionais locais.

A globalização neoliberal se torna hegemônica com o Consenso de Washington, disseminado na década de 1990 e patrocinado pelos membros do G-7, tendo por base quatro princípios: (1) economia neoliberal; (2) Estado mínimo; (3) democracia liberal e (4) primazia do Estado de Direito e do sistema judicial (SANTOS, 2006). Especificamente a gênese do chamado Consenso funda-se nas recomendações econômicas do governo dos Estados Unidos, por meio do mandato de Ronald Reagan (ver BATISTA, 1994) e das instituições financeiras internacionais sob a liderança do Fundo Monetário Internacional (FMI) e do Banco Mundial. Em resumo, a iniciativa objetivava disseminar um conjunto de recomendações voltadas para o crescimento econômico de países em desenvolvimento da Ásia e da América do Sul em contrapartida ao recebimento de empréstimos externos.

No âmbito da globalização neoliberal, as economias locais devem estar subordinadas à economia global. Segundo Santos (2006), esse conjunto de medidas visava liberalizar os fluxos de capitais e de investimentos externos, bem como incentivar as privatizações para reduzir a influência do Estado na economia. Com as privatizações das empresas estatais, os Estados assumem o papel de reguladores do mercado e, sobretudo, permitem a entrada das corporações transnacionais em setores, antes protegidos, dos mercados domésticos.

Nas diretrizes do Consenso de Washington, observa-se um globalismo localizado que concretiza o predomínio dos fluxos financeiros especulativos e de investimentos externos diretos por atores privados apoiados por Estados desenvolvidos do Norte. O modelo de Estado regulador, sem participação no mercado, tem se mostrado contraditório, pois fortalece o mercado e este impõe uma lógica de produção e consumo que enfraquece a sociedade e a capacidade do Estado de formular e implementar políticas sociais.

Sob a alegação de minimizar o papel do Estado que se mostra incapaz para as práticas de mercado, as instituições financeiras internacionais com sede em Washington pretendem reduzi-lo a ponto de comprometer o exercício de suas funções clássicas, entre elas a segurança nacional. Isso se converte em interferência global (ou internacional) no local, erodindo a soberania dos países em desenvolvimento do Sul (BATISTA, 1994). 
Na democracia liberal, os direitos civis e políticos devem se sobrepor aos direitos sociais e econômicos (SANTOS, 2006), contudo os indivíduos e a sociedade tornaram-se reféns da ação de atores privados com interesses capitalistas. Ilustra este quadro a corrupção instalada no setor público, mas também no setor privado, que culminou na crise econômica de 2008 (BROWN e CLOKE, 2011).

A primazia do Estado de Direito e do sistema judiciário sob a lógica do consenso visa estabelecer garantias legais para o empreendimento da democracia liberal e da economia neoliberal, por meio de mecanismos que garantam às empresas e aos consumidores a solução dos seus litígios (SANTOS, 2006). No entanto, estas garantias geram disputas entre esferas do direito (público e econômico) internacional e nacional, porque desconsidera particularidades culturais, geográficas e econômicas de sociedades locais. O neoliberalismo, desde a década de 1980, propunha alterações políticas insustentáveis para os Estados no longo prazo. Como resultado disso, sucessivas crises financeiras ocorreram no final da década de 1990, dificultando o desenvolvimento econômico (GRUGEL, RIGGIROZZI e THIRKELL-WHITE, 2008).

Mesmo no âmbito do conceito de desenvolvimento (dito) sustentável, Banerjee (2003) considera que as organizações governamentais internacionais, tais como Organização das Nações Unidas (ONU), Organização Mundial do Comércio (OMC), Banco Mundial e FMI, são agentes que operam em consonância com interesses de corporações transnacionais. O autor reconhece práticas colonialistas imperialistas do FMI, OMC e Banco Mundial, uma vez que estes agentes exercem poder de influência sobre os países do chamado Terceiro Mundo com a imposição de metas de desenvolvimento e de austeridade, com base em uma retórica que implementa o modelo de desenvolvimento privilegiado por corporações transnacionais e Estados do G-7. Apesar dos sucessivos avanços tecnológicos, o modelo hegemônico de desenvolvimento não reduz desigualdades, mas amplia os problemas ambientais e sociais locais (BANERJEE, 2003).

Por meio dessa visão crítica do modelo de desenvolvimento ocidental, e considerando a sua escala global, percebe-se que os problemas centrais têm raízes epistemológicas e ontológicas, conforme destacado por autores latino-americanos (MIGNOLO, 2005; ESCOBAR, 2004, 2005 e 2011; DUSSEL e IBARRA-COLADO, 2006; IBARRA-COLADO, 2006; QUIJANO, 2012). À medida que tenta conciliar forças opostas, como natureza e economia capitalista, e universalizar conceitos e significados de natureza e de capitalismo, dicotomiza pobres e ricos com base em métricas de pobreza e riqueza material. Consequentemente, os descontentes com o modelo hegemônico são rotulados de insurgentes, e a polarização do discurso passa a ser informada pelas noções de bem e mal em paralelo à cooptação dos saberes tradicionais. Segundo essa visão crítica, é o modelo de pensamento que está em crise, portanto devemos desacreditar a inevitabilidade do modelo dominante (ESCOBAR, 2004).

Para Escobar (2005), os processos de globalização alteram significativamente a dinâmica da cultura e da economia em escala local. No discurso da globalização, o global é equivalente ao espaço e o local é o equivalente ao lugar. Dessa forma, o espaço e o lugar são dimensões distintas para que sejam observados o mesmo fenômeno da globalização e seus efeitos no contexto, ante um processo de desenvolvimento. Essas são também dimensões importantes para se repensar um modelo do lugar que coexista com o modelo global hegemônico. Sobretudo porque a experiência de desenvolvimento segundo o modelo dominante usualmente resulta em um afastamento do lugar (ESCOBAR, 2005).

De forma mais contundente, Mignolo (2005) afirma a necessidade de desprendimento das vinculações da racionalidademodernidade com o colonialismo, e do imperialismo inserido na retórica da democracia e, definitivamente, de todo poder não constituído por decisão livre de gente livre. As Constituições Plurinacionais do Equador e Bolívia ilustram particularmente bem esse exercício de desprendimento.

\section{CONCEITO E MATERIALIDADE DOS SABERES TRADICIONAIS DO BUEN VIVIR}

Neste ponto, refinam-se os questionamentos deste ensaio: (1) existiria alternativa para o progresso do Sul frente ao modelo hegemônico de desenvolvimento? (2) Como um possível constructo alternativo se ajustaria ao contexto do capitalismo global?

O Buen Vivir, radicado precisamente nos povos ancestrais andinos, foi originalmente chamado Suma Quamaña em Aymara, Sumak Kawsay em Quéchua (MAMANI, 2010), Kume Mogen em Mapuche e Teko Kavi em Guarani (ESTERMANN, 2013). Em português, pode-se compreender o conceito como sendo o viver pleno ou viver plenamente, em uma noção de amplitude do conceito. Alguns autores referem-se ao termo Vivir Bien como sinônimo de Buen Vivir (e.g. ESCOBAR, 2010; 
ESTERMANN, 2013) e aos termos Vivir Bien e bienestar (ACOSTA, 2008). Contudo notamos uma distinção no uso dos termos por Acosta (2010), visto que os emprega com o sentido de resultante do Buen Vivir, ou seja, do Buen Vivir como ontologia resulta um Vivir Bien ou um bienestar como aplicação nos campos da vida.

Como ontologia, apesar dos poucos estudos empíricos realizados, o Buen Vivir é um projeto em construção que vê possibilidade de resistência ao modelo dominante e se configura como uma voz não apenas de resistência, mas também de alternativa às civilizações - portanto tem sido contra-hegemônica. Considera-se a concepção de contra-hegemonia neste ensaio como resultado de "[...] um trabalho organizado de mobilização intelectual e política contra a corrente, destinado a desacreditar os esquemas hegemônicos e fornecer entendimentos alternativos credíveis da vida social”. (SANTOS, 2014, p. 33-36). Observa-se que o contra-hegemônico não pretende a hegemonia

O Buen Vivir é crítico da racionalidade do desenvolvimento econômico, de mercado e do progresso (GUDYNAS, 2011). Em consonância com o cosmopolitismo insurgente apresentado por Santos (2006, p. 397), "[...] é a resistência transnacional organizada contra as trocas desiguais produzidas ou intensificadas por localismos globalizados e globalismos localizados". As resistências se materializam na internacionalização de representações de vitimados, como, por exemplo, trabalhadores, organizações não governamentais progressistas, movimentos feministas, indígenas e outros, que merecem atenção sobre os antecedentes e contexto em que se originaram.

Como resultado desses movimentos, os representantes indígenas foram incluídos como partícipes das assembleias constituintes da Colômbia, Equador, Nicarágua, Panamá e Guiana (PUIG, 2010). Inclusão que culminou em constituições plurinacionais com reconhecimento de direitos dos povos originários locais. A participação indígena em escala local não se repete nas escalas regional e global, como observado por Banerjee (2011). No entanto, os documentos que resultaram dessa participação reconhecem o multiculturalismo e os indígenas como povo distinto no local; preservam o direito consuetudinário indígena como oficial, e o direito de propriedade; garantem o status oficial da língua indígena, a educação bilíngue; e o direito de criação de territórios autônomos (VAN COTT apud PUIG, 2010). Estes direitos constam explicitamente nas constituições da Bolívia e do Equador (PUIG, 2010) e se materializam no conjunto de ações para a inserção da língua indígena na sociedade boliviana (MINISTERIO DE EDUCACIÓN BOLIVIANA, 2017), na resistência local (Cochabamba) ao poder capitalista sobre a gestão da água (OTTO e BOHM, 2006; PINTO, 2017), na resistência à construção de estrada em área indígena (SPULDAR, 2011) e na criação de projetos e ações educacionais para promover uma melhor relação entre ser humano e natureza no Equador (MINISTÉRIO DA EDUCAÇÃO DO EQUADOR, 2017a; 2017b).

Mas o Buen Vivir não é apenas um movimento insurgente (SANTOS, 2006) com um possível constructo residente em movimentos autônomos de resistência. Como afirma Puig (2010), após a convenção 169 da Organização Internacional do Trabalho (OIT), de 7 de junho de 1989, e da declaração das Nações Unidas sobre os direitos dos povos indígenas, em setembro de 2007 (que versam sobre os direitos, independência, autonomia e diversidade dos povos indígenas e tribais, ver MAMANI, 2010, p. 08), o conceito foi incorporado no Estado de Direito nas Constituições do Equador e Bolívia. Ambas promovem questionamentos profundos sobre a noção de Universalidade, Progresso, Desenvolvimento, Natureza, Indivíduo e Sociedade e por isso não estão livres de tensões quando confrontadas com o sistema hegemônico. Nessas tensões estão algumas das respostas ao segundo questionamento deste ensaio.

Para León (2008), o Buen Vivir sintetiza visões e práticas ancestrais andinas, debates e propostas atuais, pensamentos críticos e lutas sociais recentes que representam a busca de alternativas em resposta ao modelo de desenvolvimento e de civilização reconhecidamente insustentável. O processo de construção do Buen Vivir questiona noções tidas como intransitivas, tais como progresso, crescimento, desenvolvimento e bem-estar, conforme ilustra o conceito de Vivir Bien.

Das "verdades" produzidas pelo poder hegemônico eurocêntrico, a noção de "universalidade" significa uma única forma de compreender e explicar o mundo, bem como de vivê-lo. Essa noção é questionada pelo Buen Vivir, que a contrapõe com a de multiverso, com o significado de pluralidade de possibilidades para compreender, explicar e viver o mundo, reconhecendo o inter-relacionamento entre tudo que nele existe e considerando que o equilíbrio e harmonia são importantes para a sociedade, com abrangências políticas, econômicas, culturais e sociais (MAMANI, 2010). Consonante com a noção de multiverso, Escobar (2011, p. 311) apresenta alguns princípios para um pós-desenvolvimento que contemplam um "pluriverso de configurações socioculturais" e "cosmovisões relacionais". Mais especificamente Dussel e Ibarra-Colado (2006) afirmam que pluriverso é a possibilidade de acomodar no mundo uma diversidade cultural, com identidades preservadas e, ao mesmo 
tempo, a capacidade de assimilar e escolher o que da modernidade é conveniente em termos de meios de produção, formas de consumo, organização social, práticas educacionais e de saúde.

Na filosofia andina, ecosofia (ESTERMANN, 2013), ou cosmovisão relacional em um pluriverso (DUSSEL e IBARRA-COLADO, 2006; ESCOBAR, 2011) e multiverso (MAMANI, 2010), são premissas do Buen Vivir e se opõem à racionalidade mecanicista, utilitarista ocidental centrada em unidades isoladas. A visão cósmica é centrada nas relações entre tudo que existe, ou seja, não é centrada nas partes, nos entes, na substância, mas na conexão e relacionamento existentes entre tudo que está no cosmos. São os elementos dessa filosofia que revelam uma ontologia resistente e alternativa: os conceitos de relacionalidade, complementaridade, correspondência, reciprocidade e ciclicidade. Tais conceitos do Buen Vivir podem unir-se aos esforços constitutivos de epistemologias do Sul para um processo de desenvolvimento local, regional e global, no qual o papel das organizações internacionais deve ser o de articular a recursividade da gestão-desenvolvimento e desenvolvimento-gestão (para outras interfaces entre gestão e desenvolvimento que afastam a reificação da primeira pelo segundo, ver JUSTEN e NETO, 2013).

Na ética do Buen Vivir, não tem amparo a racionalidade burocrática ocidental que separa o ser humano da natureza, atribuindo-Ihe superioridade e, consequentemente, a capacidade de dominá-la e explorá-la sem considerar a finitude de recursos. Para León (2008), o Buen Vivir supõe uma relação harmônica entre os seres humanos e a natureza. Choquehuanca (2010) informa que o Buen Vivir significa recuperar a cultura da vida, a vida em harmonia com a natureza, em que se reconhece que todos os seres vivos são parte e não há nada separado dela.

Acosta (2010), ao reforçar as ideias apresentadas por León (2008), Choquehuanca (2010) e Salgado (2010), explicita em termos legais a abordagem do Buen Vivir que reconhece a natureza como sujeito de direito, assim como o ser humano. Nesses termos, surgem dois grupos de direitos (humanos e da natureza) que reconhecem a centralidade conjunta de ser humano e natureza. Um exemplo da ética do Buen Vivir foi a aprovação pela ONU, em 28 de julho de 2010, da proposta boliviana que declara a água segura e o saneamento como direito humano. Mais especificamente, o direito declarado do natural (a água) de não receber poluentes e manter-se saudável. Desse modo, os direitos não se sobrepõem, mas interagem de forma integral ao assumir o Buen Vivir como igualmente prioritário ao desenvolvimento.

Essa posição de igualdade, tendo como base a questão da água, pode ser entendida como uma conquista gradual da resistência de múltiplos agentes sociais bolivianos em Cochabamba (Coordenadora de Defesa da Água e da Vida), que desde 1999 movimentaram-se para rejeitar a privatização e exploração da água por um grupo econômico multinacional. Assim, são fatos sociais relevantes - desdobramentos da ação popular informada por uma ética do Buen Vivir, contrária ao modelo de desenvolvimento neoliberal - tanto a resistência, que contou com greves, reuniões em praça pública e uma simbólica tomada de poder em Cochabamba, quanto a assinatura de um novo acordo, em 9 de abril de 2000, entre representantes do governo e a Coordenadora para oficializar o restabelecimento local do Servicio Municipal de Agua Potable y Alcantarillado COCHABAMBA - SEMAPA (organização boliviana responsável pelo abastecimento de água), sob uma diretoria formada por representantes do governo, da Coordenadora e do sindicato (OTTO e BOHM, 2006).

A disputa por direito e controle da água na Bolívia exemplifica como ONU, FMI e OMC promovem investimentos de corporações do Norte para o Sul, abundante em água doce (Brasil, Paraguai, Uruguai e Argentina estão sobre o maior reservatório subterrâneo de água do mundo - o Aquífero Guarani - ver PINTO, 2017). E mesmo sendo a água um requisito obrigatório para a manutenção do direito humano à vida (FERREIRA, 2011), pretende-se explorá-la com fins capitalistas.

Outros exemplos de resistência aos avanços do desenvolvimento neoliberal em escala regional estão presentes no setor de construção civil. Na Bolívia, a empreiteira brasileira OAS foi impedida de construir uma rodovia por força de lei que transformou em "zona intocável" a reserva indígena de Tipnis (SPULDAR, 2011).

No caso equatoriano, dois regimes convivem com a mesma importância hierárquica, sendo o primeiro o regime do Buen Vivir, que contempla questões de inclusão e equidade, como a educação, saúde, moradia e cultura, mas também a biodiversidade e recursos naturais. O segundo é o regime do desenvolvimento, que, de acordo com Gudynas e Acosta (2011, p. 77), é definido como "[...] o conjunto organizado, sustentável e dinâmico dos sistemas econômico, político, socioculturais e ambientais que garantam a realização do Buen Vivir". Portanto, o Buen Vivir figura como um direito que demanda alterações nas estratégias de desenvolvimento (GUDYNAS e ACOSTA, 2011) do Equador. 
Como iniciativa para a construção do Buen Vivir, o Equador criou em 2014 o projeto Escolas do Buen Vivir (coexistente ao sistema de ensino), para fomentar a mudança de atitude sobre práticas e cuidados com o entorno natural e social (MINISTÉRIO

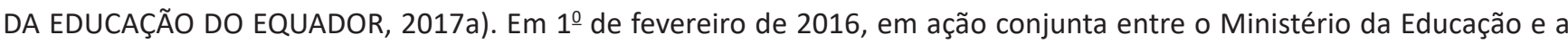
Secretaria do Buen Vivir, foi lançado com distribuição gratuita o "Libro de todos los niños", para a disseminação de valores como honestidade, respeito, gratidão, perseverança, humildade, bondade, generosidade, responsabilidade, inovação, amizade, perdão e solidariedade (MINISTÉRIO DA EDUCAÇÃO DO EQUADOR, 2017b).

No contexto boliviano, o Buen Vivir está presente na base fundamental do Estado, que reconhece na sociedade plural os princípios ético-morais dos povos indígenas, tais como: não ser fraco, mentiroso, ladrão, viver bem, vida harmoniosa, terra sem mal e caminho ou vida nobre. Estes princípios de origens aymara, quechua e guarani estão na mesma hierarquia dos princípios de igualdade, inclusão, dignidade, liberdade e solidariedade, e definem também a inter-relação entre mercado, Estado e sociedade, na qual o mercado não provê todas as soluções e ao Estado cabe promover a dinâmica construtiva entre atores sociais (GUDYNAS e ACOSTA, 2011).

Em termos mais amplos, Acosta (2010) enfatiza que em desenvolvimento não há a noção de pobreza associada a carência de bens materiais. Ao contrário, há um processo de construção contínuo e reproduzível de melhorias sociais. Com essa abordagem, um dos grandes desafios do Buen Vivir é a implementação, com um caráter instrumental e com efeitos práticos, de melhorias sociais. Portanto Acosta (2010) parte da definição constitucional de economia social e solidária, em que o desafio deve ser construir relações de produção, intercâmbio e cooperação para além da eficiência, buscando qualidade e suficiência da sociedade. Nesse contexto almejado, que difere da ética moderna de acumulação material individual, configura-se a construção de um novo papel para a economia. Contudo não se pretende construir um Estado controlador, ao mesmo tempo que não se permite que a sociedade seja governada pelo mercado (ACOSTA, 2010).

A economia comunitária complementar é apresentada por Mamani (2010) também como uma possibilidade de organização. Este autor parte da equiparação de homem e natureza como sujeitos de direito, para esboçar uma nova relação na dinâmica de produção e distribuição dos produtos em uma comunidade. No entendimento ancestral andino, comunidade significa uma economia sem fins exclusivos de acumulação de capital, não define ricos e pobres, os meios de produção agem para o equilíbrio da vida de todos os seres vivos, já que natureza e homem são seres vivos e parte de uma unidade. Observam-se limites para o manejo da natureza e uma mudança na finalidade do trabalho, que migra da acumulação para a manutenção da vida. O autor aponta para uma relação de comunhão e mérito entre homem e natureza num contexto de grupo, na qual o parâmetro para medição é a quantidade de integrantes do grupo, seja a comunidade ou a família como unidade menor, e o objetivo fim é viver bem. Essa dinâmica aproxima-se do conceito de desenvolvimento sustentável (conforme problematiza BANERJEE, 2003), pois declara no seu objetivo a busca pelo desenvolvimento no qual se reconhece igual hierarquia entre as necessidades da natureza e do homem.

O governo boliviano promove a economia comunitária por meio da Feira de Preço e Peso Justos em diversas partes do país (MINISTÉRIO DE DESENVOLVIMENTO E TERRAS, 2017), o que aproxima os produtores e a sociedade para evitar os intermediários na cadeia de distribuição, garantindo, assim, preços menores.

Outro exemplo de materialidade do Buen Vivir, que se opõe ao modelo hegemônico, está no modo de produção agrícola de multicultivo (em oposição ao monocultivo), porque respeita a capacidade de regeneração da terra, destruída pela produção especializada em larga escala. Contudo isso requer um marco jurídico que o viabilize, reconhece Mamani (2010), pois o multicultivo contraria a lógica individualista. O autor dá pistas de instituições do povo Aymara que podem inspirar políticas públicas para tal solidariedade econômica: Ayni (complementaridade, ajuda mútua, reciprocidade e interdependência); Tampu (espaços comuns onde se dispõem produtos e alimentos aos necessitados); Tumpa (assumir responsabilidades conjuntas e transparência); Muyt'a (assumir responsabilidades por turno); Khuskha (equilíbrio dinâmico, distribuição e redistribuição segundo a necessidade) e Wajt'a (importância das cerimônias para realizar qualquer atividade produtiva, econômica, social, etc.) (MAMANI, 2010).

Embora se reconheça a necessidade de um marco regulatório para o multicultivo, não obstante algumas ações do governo da Bolívia promovem um melhor manejo da agricultura e a valorização de produtores tradicionais, como a capacitação para o controle de pragas e doenças oferecida aos 320 produtores e produtoras das comunidades de Mejillones, Bracha $\mathrm{H}$, Bracha I, Luz Porvenir, e o distrito de Popoy no município de Palos Blancos (MINISTÉRIO DE DESENVOLVIMENTO E TERRAS, 2017). 
A responsabilidade do Estado de administrar para distribuir a riqueza gerada está presente na Constituição do Equador. Segundo Acosta (2010), versa sobre o reconhecimento de diversas formas de se fazer economia, com participação do Estado e da iniciativa privada, em conjunto ou separadamente. No entanto, consolida o monopólio público dos recursos estratégicos a fim de dar a destinação que considera adequada segundo o Buen Vivir.

Essa sinalização ao mercado cria a necessidade de um fluxo interno de capital capaz de suprir as necessidades da sociedade. Nesse caso, a proposta na Constituição do Equador é de uma arquitetura financeira com serviços de ordem pública, por meio do incentivo de um banco de fomento que aglutine as poupanças nacionais e esteja orientado à promoção do desenvolvimento social (ACOSTA, 2010).

De acordo com Mamani (2010), a construção do Buen Vivir passa também pela estrutura educacional, pela necessidade de uma emancipação epistemológica que liberte o homem da racionalidade ocidental dominante. Em termos práticos, na Bolívia o Estado implementou legislação que determina a inclusão dos saberes tradicionais no currículo escolar. Estão em fase de planejamento (com a participação do Instituto Plurinacional de Estudo de Línguas e Culturas, da Universidade Pedagógica, da Coordenadora Nacional comunitária educacionais dos povos originários e do Ministério da Educação Boliviana), ações como a criação de um atlas linguístico dos povos indígenas, registro de léxicos, fóruns permanentes de linguística conduzidos por bolivianos em diversos espaços, dentre outros mecanismos de desenvolvimento da língua indígena na sociedade (MINISTERIO DE EDUCACÍON BOLIVIANA, 2017). Cabe destacar que Santos (2009) enfatiza a necessidade de descolonização dos saberes, para que a colonialidade epistêmica (DUSSEL e IBARRA-COLADO, 2006) não se perpetue nas sociedades latino-americanas.

Por fim, Gallegos (2010) considera que o Buen Vivir é um bioigualitarismo republicano, pois reconhece os direitos da natureza, amplia a justiça socioeconômica e apoia a institucionalidade em que interagem o Estado e os cidadãos. Por mais ousado que possa parecer, fica evidente que o Buen Vivir representa uma voz de resistência, bem como uma contraposição (ou alternativa) em relação ao modelo de desenvolvimento hegemônico. O grande desafio aponta para a criação e implementação de políticas públicas capazes de acomodar o anseio social e as pressões do capital.

\section{CONSIDERAÇÕES FINAIS}

Este ensaio teórico problematiza o Buen Vivir para "[...] co-construir o amálgama pluriversal de conhecimentos" (COOKE e FARIA, 2013, p. 12). Com o objetivo de atingir tal propósito, apresenta uma visão crítica da globalização neoliberal, que dissemina um modelo de desenvolvimento ineficaz para o bem-estar social, sobretudo para os espaços vulneráveis do Sul. Sem a ambição de esgotar o tema e/ou universalizar verdades, ilustra a crescente possibilidade de espaços para a diversidade de modos de desenvolvimento com base nos exemplos do Equador e da Bolívia.

A ideia de uma globalização neoliberal imposta por organizações internacionais encontra oposição em políticas de proteção à soberania de governos latino-americanos, que aceitaram parcialmente o Consenso de Washington enquanto buscavam alternativas de desenvolvimento. Entendemos ser essa uma arena fecunda para questionamentos de como são utilizados os processos de racionalização técnica e substantiva no pensamento organizacional, que pode conduzir uma discussão sobre os limites da globalização neoliberal e, por exemplo, a determinação do que seria globalizável para o Sul, a fim de preservar experiências de desenvolvimento local.

Ao evidenciar limites do progresso, crescimento, desenvolvimento e bem-estar (LEÓN, 2008), o Buen Vivir questiona o individualismo maximizador de utilidade. Ao mesmo tempo, permite a discussão sobre o papel das organizações internacionais e dos Estados nacionais num processo de desenvolvimento local que produza menos desigualdades. A institucionalização do Ayni (complementaridade, ajuda mútua, reciprocidade e interdependência) pode ser uma importante fonte conceitual para promover arranjos no sistema produtivo que combinem a ação dos agentes públicos e privados em benefício dos locais.

Na defesa pela água na Bolívia, nota-se uma resistência social organizada e ampla (temática relevante para os estudos organizacionais, OTTO e BOHM, 2006; FERREIRA, 2011; PINTO, 2017), que revela a Ayni na ação social liderada pela Coordenadora de Defesa da Água e da Vida com o intuito de restabelecer o Estado desejado pelo povo. A luta pelo direito à água, como bem comum, mostra a possibilidade de se organizar movimentos de resistência com a participação de múltiplos agentes, assim como de admitir arranjos sociais com mais participação do povo nas decisões das políticas públicas, para fazer valer os interesses em preservar da água e outros elementos da natureza vitais para o ser humano. 
O bem comum (e público) privilegiado na luta pela água na Bolívia contrasta com a instalação de plantas de papel e celulose no Cone Sul da América. A disputa jurídica em escala regional (entre Brasil, Argentina e Uruguai) que resultou da instalação das plantas não impediu a alteração no modo de vida de muitas famílias, apesar da mobilização dos movimentos sociais e ambientais (VENTURA e MIOLA, 2009). Esse exemplo revela uma diferença de eficácia da mobilização social na resistência ao modelo neoliberal, e em defesa da vida, que pode ser em parte atribuída à visão de mundo dos respectivos povos, com melhores resultados para os andinos.

Tanto no questionamento que privilegia a preservação de formas locais de desenvolvimento, quanto na crítica à maximização da utilidade, a dialógica entre gestão e desenvolvimento - segundo Justen e Neto (2013), na qual a organização tem papel de articuladora da simbiose ser humano/ecossistema - recomenda a adoção do Buen Vivir para uma compreensão da realidade que reforce a pluriversalidade de saberes e de modos de vida.

Com base na ética do Buen Vivir, podemos pensar em formulação e implementação de políticas públicas que conjuguem os esforços das escalas global, regional e local e, ao mesmo tempo, diminuam a assimetria de poder entre mercado, Estado e sociedade, a fim de tornar as instituições Aymara, Ayni, Tampu, Tumpa, Muyt'a, Khuskha e Wajt'a (MAMANI, 2010) práticas sociais de resistência aos avanços das práticas de mercado que aprofundam as desigualdades.

O Buen Vivir funda-se em visões de mundo distintas e precedentes (cosmovisão relacional, ecosofia, multiverso, pluriverso e bioigualitarismo) à globalização neoliberal, portanto, um projeto resistente e alternativo sem a pretensão de substituir o modelo de desenvolvimento hegemônico. Requer a sensibilidade e a percepção do indivíduo para a vida, para uma educação comunitária produtiva que não distingue ser humano e natureza e impõe uma relação de filiação entre o humano e a mãe Terra (MAMANI, 2010). Segue uma lógica de resistir sem se calar à aceitação do neoliberalismo: não silenciar significa buscar nos saberes tradicionais conjuntos ético-morais capazes de viabilizar uma forma de organização social que supra as carências humanas com equidade e sustentabilidade.

No Equador, as Escolas do Buen Vivir semeiam as bases de uma ética alternativa e de coexistência. Embora ainda exista um distanciamento entre o texto constitucional com base no Buen Vivir e as práticas concretas no Equador (FERNANDEZ, PARDO e SALAMANCA, 2014), a persistência das tensões entre o Buen Vivir e o modelo de desenvolvimento hegemônico reforça a realidade de enfraquecimento social (SALGADO, 2010). Portanto não há, ao menos no Equador, um ajustamento do constructo do Buen Vivir à ordem global, mas sim o desafio de desenvolver políticas públicas que transformem práticas de governo, de mercado e da sociedade.

Informados pela busca de certo equilíbrio entre atores sociais (GUDYNAS e ACOSTA, 2011) nos países latino-americanos citados, é possível vislumbrar a necessidade de maior redistribuição de forças entre o Estado, o mercado e a sociedade, ainda que isso acentue as tensões por considerar a translocalidade (BANERJEE, 2011) dos fenômenos ambientais e sociais e a representação individual e coletiva na democracia direta (VITALE, 2004).

Da materialidade dos localismos globalizados, conforme sugere Santos (2006), o Buen Vivir exerce resistência pela inserção no currículo escolar boliviano dos aspectos culturais indígenas, que podem influenciar no longo prazo a identidade e consciência da diversidade, do multiverso e/ou pluriverso. Tal inserção pode converter-se em possível força frente às constantes investidas das corporações e do governo por meio de hábitos, música, culinária, educação e demais instrumentos de poder brando da colonização eurocêntrica e da globalização neoliberal euro-americana.

O resgate e manutenção do conceito de multiverso também podem contribuir para afastar os globalismos localizados (SANTOS, 2006). Das instituições do povo Aymara, descritas por Mamani (2010), o Tampu (espaços comuns onde se dispõem produtos e alimentos aos necessitados) eliminaria a relação diádica (comercial) entre produtor-consumidor. Nesta relação ainda que prevalente, nota-se que, na Bolívia, a Feira do Preço e Peso Justos altera a cadeia de distribuição ao remover intermediários e aproximar produtor e sociedade. Este contexto semeia uma concepção mais abrangente de consumo, importante para pesquisas focadas em desenvolvimento local, movimentos anticonsumo e estudos organizacionais, sobretudo quanto ao papel das organizações internacionais nessas localidades.

Por fim, esta discussão articula os âmbitos econômico, político, social e cultural e contém necessariamente visões de longo prazo importantes para as organizações capazes de produzir riqueza e atender demandas sociais emergentes. Como contribuição do ensaio para este debate, defende-se uma maior preocupação dialógica por parte das organizações internacionais e nacionais com o desenvolvimento local e com a manutenção dos saberes tradicionais. 


\section{REFERÊNCIAS}

ACOSTA, A. El Buen Vivir, una Oportunidad por Construir. Revista Ecuador Debate, n. 75, p. 33-48, 2008.

ACOSTA, A. El Buen Vivir en el camino del post-desarrollo. Una lectura desde la constitución de Montecristi. Policy Paper, 9, Oct. 2010, Fundación Friedrich Ebert, 2010.

BANERJEE, S. B. Who Sustains Whose Development? Sustainable Development and the Reinvention of Nature. Organization Studies, n. 24, p. 143, 2003.

BANERJEE, S. B. Voices of the Governed: towards a theory of the translocal. Organization, n. 18, v. 3 p. 323-344, 2011.

BATISTA, P.N. O Consenso de Washington e a visão neoliberal dos problemas latino-americanos. In: LIMA SOBRINHO, B. et al. Em defesa do interesse nacional: desinformação e alienação do patrimônio público. São Paulo: Paz e Terra, 1994.

BOFF, L. ¿Vivir Mejor o El Buen Vivir?, 2009. Disponível em: <http:// www.otrodesarrollo.com/buenvivir/buenvivir_leonardoboff.pdf>. Acesso em: 14 set. 2017.

BROWN, E.; CLOKE, J. Critical Perspectives on Corruption: an overview. Critical Perspectives on International Business, v. 7, n. 2, p. 116-124, 2011.

CHOQUEHUANCA, C. Hacia la reconstrucción del Vivir Bien. America Latina en Movimiento, ALAI, n. 452, p. 6-13, 2010.

COOKE, B. The Managing of the (Third) World. Organization, v. 11 n. 5, p. 603-629, 2004.

COOKE, B.; FARIA, A. Desenvolvimento, Administração e Imperialismo do Atlântico-Norte: para Eduardo Ibarra-Colado. Cadernos EBAPE.BR, v.11, n. 2, Editorial, Rio de Janeiro, jun., 2013.

DUSSEL, H.; IBARRA-COLADO, E. Globalization, Organization and the Ethics of Liberation. Organization, v.13 n. 4, p. 489-508, 2006.

ESCOBAR, A. Beyond the Third World: imperial globality, global coloniality and anti-globalisation social movements. Third World Quartely, v. 25, n. 1, p. 207-230, 2004.

ESCOBAR, A. O lugar da natureza e a natureza do lugar: globalização ou pós-desenvolvimento? In: LANDER, E. (Org.). A colonialidade do saber. Eurocentrismo e ciências sociais. Perspectivas latino-americanas. Buenos Aires: Clacso, 2005. p. 133-168.

ESCOBAR, A. Latin America at a Crossroads: Alternative Modernizations, Post-liberalism, or Post-development? Cultural Studies, v. 24, n. 1, p. 1-65, jan. 2010.

ESCOBAR, A. Una minga para El posdesarrollo. Signo y Pensamiento 58 - Puntos de vista, v. XXX, p. 306-312, jan./jun. 2011.

ESTERMANN, J. Ecosofía andina: un paradigma alternativo de convivencia cósmica y de vivir bien. FAIA, v. II, n. IX-X, p. 1-21, 2013.

FARIA, A. Reframing Diversity Management. In: BENDL, R.; BLEIJENBERGH, I.; HENTTONEN, E.; MILLS, A. J. The Oxford Handbook of Diversity in Organizations. Oxford: Oxford University Press, 2015. p. 127-149.

FERNANDEZ, B.S.; PARDO, L.; SALAMANCA, K. El buen vivir en Ecuador: ¿marketing político o proyecto en disputa? Revista de Ciencias Sociales, n. 48, p. 101-117, jan. 2014.
FERREIRA, L. Do acesso à água e do seu reconhecimento como direito humano. Revista de Direito Público. v. 6, n. 1, p. 55-69, jan./abr. 2011.

GALLEGOS, R. Los Nuevos Retos de America Latina. Socialismo del Sumak Kawsay o biosocialismo republicano. Senplades, p. 55-74, 2010.

GRUGEL, J.; RIGGIROZZI, P.; THIRKELL-WHITE, B. Beyond the Washington Consensus? Asia and Latin America in Search of More Autonomous Development. International Affairs, v. 84, n. 3, p. 499-517, 2008.

GUDYNAS, E. Buen Vivir: Germinando alternativas al desarrollo. ALAI, n. 462, p. 1-20, fev. 2011.

GUDYNAS, E; ACOSTA, A. La renovación de la crítica al desarrollo y el buen vivir como alternativa. Utopía y Práxis Latinoamericana, v. 16, n. 53, p. 71-83, abr./jun. 2011.

IBARRA-COLADO. Organization Studies and Epistemic Coloniality in Latin America: Thinking Otherness from the Margins. Organization, v. 13, n. 4, p. 468-488, 2006.

JUSTEN, C. E.; NETO, L. M. Gestões do desenvolvimento e desenvolvimento da gestão: da unilateralidade reificada à dialogicidade da simbiose homem/natureza. Cadernos EBAPE.BR, v. 11, n. 2, p. 295-310, 2013.

LEÓN, M. "El "buen vivir": objetivo y camino para otro modelo". La Tendencia, Quito, 2008.

MAMANI, F. Buen Vivir/Vivir Bien. Filosofia, políticas, estrategias y experiencias regionales andinas. CAOI, 2010.

MIGNOLO, W. El pensamiento dês-colonial, desprendimiento y apertura: un manifesto. Tristes Trópicos, 2005.

MINISTÉRIO DA EDUCAÇÃO DO EQUADOR, 2017a. Disponível em: <https:// educacion.gob.ec/que-es-el-buen-vivir/>. Acesso em: 07 abr. 2017.

MINISTÉRIO DA EDUCAÇÃO DO EQUADOR. 2017b. Disponível em: $<$ https://educacion.gob.ec/ministerio-de-educacion-y-secretaria-del-buen-vivir-lanzan-herramienta-para-el-aprendizaje-de-valores-en-instituciones-educativas/>. Acesso em: 07 abr. 2017.

MINISTÉRIO DE DESENVOLVIMENTO E TERRAS. 2017. Disponível em: http://www.ruralytierras.gob.bo/. Acesso em: 07 abr. 2017.

MINISTERIO DE EDUCACIÓN BOLIVIANA. 2017. Disponível em:<http:// www.minedu.gob.bo/index.php/todas-las-noticias/1414-educacion-elaboran-plan-de-accion-para-el-ano-internacional-de-las-lenguas-indigenas-2019>. Acesso em: 02 abr. 2017.

MISOCZKY, M. C.; BÖHM, S. Resistindo ao desenvolvimento neocoIonial: a luta do povo de Andalgalá contra projetos megamineiros. Cadernos EBAPE.BR, v. 11, n. 2, p. 311-339, 2013.

OTTO, B; BOHM, S. "The people" and resistance against international business: the case of the Bolivian "water war". Critical perspectives on international business, v. 2, n. 4, 2006.

PINTO, E. Geopolítica da Água. Revista de Geopolítica, v. 8, n. 1, p. 19-32, jan./jun. 2017.

PUIG, S.M. The Emergence of Indigenous Movements in Latin America and Their Impact on the Latin American Political Scene: Interpretive 
Tools at the Local and Global Levels. Latin American Perspectives, ed.175, v. 37, n. 6, p. 74-92, 2010.

QUIJANO, A. Bien Vivir: entre el desarrollo y la des-colonialidad del poder. Viento Sur, 2012.

SALGADO, F. Sumaq Kawsay: the birth of a notion? Cadernos EBAPE.BR, v. 8, n. 2, p. 198-208, jun. 2010.

SANTOS, B. S. Globalizations. Theory Culture Society, n. 23, p. 393, 2006.

SANTOS, B. S. Una Epistemología del Sur. La reinvención del conocimiento y la emancipación social. México: Clacso y Siglo XXI, 2009.

SANTOS, B. S. Epistemologias del Sur. Utopia y Praxis Latinoamericana, v. 16, n. 54, p. 17-39, jul./set. 2011a.

SANTOS, B. Globalization, Emerging Powers, and the Future of capitalism. Latin American Perspectives, ed. 177, v. 38, n. 2, p. 45-57, mar. 2011 b.

SANTOS, B. S. Se Deus fosse um ativista dos direitos humanos. 2. ed. São Paulo: Cortez, 2014.
SPULDAR, R. Empreiteiras brasileiras crescem no exterior, mas se envolvem em polêmicas. BBC Brasil. 2011. Disponível em: <http:// www.bbc.co.uk/portuguese/noticias/2011/10/111027_empreiteiras_rp.shtml>. Acesso em: 07 abr. 2017.

VAINER, C. Lugar, Região, Nação, Mundo: Explorações Históricas do Debate acerca da Ação Política. R.B. Estudos Urbanos e Regionais, v. 8, n. 2, nov. 2006.

VEIGA, E. Desenvolvimento Sustentável: o desafio do século XXI. Rio de Janeiro: Garamond, 2010.

VENTURA, D.; MIOLA, I. Os Efeitos da Transnacionalização sobre a Governança Regional: o Caso da Conflituosa Implantação da Indústria de Celulose no Cone Sul da América. Contexto Internacional, v. 31, n. 3, p. 391-427, set./dez., 2009.

VITALE, D. Democracia Direta e Poder Local: a Experiência Brasileira do Orçamento Participativo. In: COELHO, V.; NOBRE, M. (Orgs.). Participação e Deliberação: Teoria Democrática e Experiências Institucionais no Brasil Contemporâneo. São Paulo: Editora 34, 2004. p. 239-254.

Klaus Pereira da Silva

Mestre em Administração pela Unigranrio; Coordenador da Escola Superior de Gestão e Tecnologia da Universidade Castelo Branco (UCB), Rio de Janeiro - RJ, Brasil. E-mail: klausps.br@gmail.com 